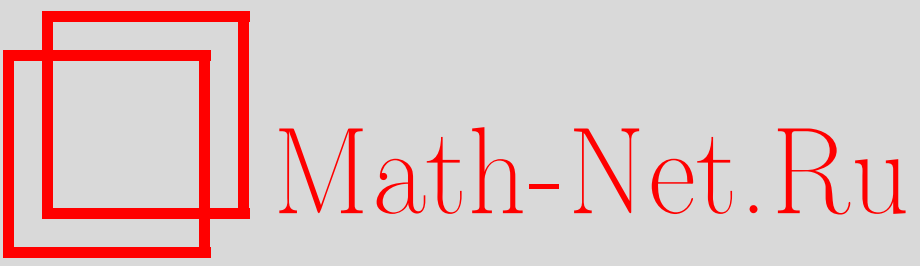

С. В. Лимаренко, Кольца с критически сжимаемыми идеалами, УМН, 2003, том 58, выпуск 2, 165-166

DOI: https://doi.org/10.4213/rm618

Использование Общероссийского математического портала Math-Net.Ru подразумевает, что вы прочитали и согласны с пользовательским соглашением

http://www.mathnet.ru/rus/agreement

Параметры загрузки:

IP : 3.85 .5 .30

26 апреля 2023 г., 13:40:48 


\title{
КОЛЬЦА С КРИТИЧЕСКИ СЖИМАЕМЫМИ ИДЕАЛАМИ
}

\author{
С.В. ЛИМАРЕНКО
}

Критически сжимаемые модули подробно рассматривались Зелшмановицем в целом ряде его работ (см., например, [1]). Он также ввел понятие слабо примитивного кольца как кольца, обладающего точным критически сжимаемым модулем. В данной работе основное внимание уделено кольцам, в которых роль точного критически сжимаемого модуля играет правьй идеал, в силу чего эти кольца являются слабо примитивными. Дополнителшно выделен случай, в котором такой идеал есть само кольцо. В работах [2] и [3] читатель может ознакомиться с аналогами вьшеупомянутых объектов в градуированном случае.

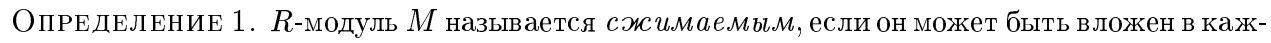
дый из своих ненулевых подмодулей.

ОПРедЕЛЕниЕ 2. Сжимаемый $R$-модул назьвается критически сжимаемым, если он не может быть вложен ни в какой из своих собственных фактор-модулей.

Сразу отметим, что ненулевой подмодуль критически сжимаемого модуля также является критически сжимаемым. Мы начнем с описания критически сжимаемых модулей.

ОПРЕДЕЛЕНИЕ 3. Модул $M_{R}$ назьвается униформным (однородным), если для любых ненулевых подмодулей $M_{1}$ и $M_{2}$ модуля $M$ их пересечение нетривиально: $M_{1} \cap M_{2} \neq 0$.

ПреДЛОЖЕНИЕ 1. Пусть $M_{R}$ - несингулярный униформный модуль, в котором $\operatorname{Hom}_{R}(M, N) \neq 0$ для кажддого ненулевого подмодуля $N_{R} \in M_{R}$. Тогда $M_{R}$ критически сжимаем.

Критически сжимаемый модул, равно как и неприводимьй, может быть сингулярным.

ПРЕДЛОЖЕниЕ 2. Следующие условия на слабо примитивное кольцо әквивалентнь:

(i) оно обладает точным несингулярным критически сжимаемым (правым) модулем;

(ii) оно обладает точныц критически сжимаемым правым идеалом.

В предыдущем предложении условие слабой примитивности кольца можно заменить на условие его первичности.

ТЕОРема 1. Пусть $R$ - первичное кольцо, тогда следующие условия на правый идеал I равносильньи.

(i) $I$ - несингулярный униформный правый идеал в $R$.

(ii) $I$ - точный критически сжимаемый правый идеал в $R$.

СледСтвиЕ. Если $S$ - правая область Оре, то $S_{S}-$ точный критически сжимаемьй модуль (как модуль над самим собой), т.е. $S$ - слабо примитивное кольцо.

В силу всего вьше сказанного, мы можем получить характеризацию некоторого специального класса слабо примитивных колец, а именно,

ПРЕДЛОЖЕНИЕ 3. Следующие условия на кольщо $R$ равносильны:

(i) $R-$ правая область Оре;

(ii) $R_{R}-$ точный критически сжимаемый модуль.

Работа выполнена при поддержке Российского фонда фундаментальных исследований (гранты № 02-01-00218, 01-02-06670). 
Широко известен тот факт, что любые два точных неприводимых (правых) модуля над примитивньм кольцом с минимальным правым идеалом изоморфны, в частности, они изоморффны этому идеалу. Можно сформулировать аналогичньй результат и для слабо примитивных колец. Максимум, на что мы можем расчитывать, - это вложение одного модуля в другой. Ни о каком изоморфизме речи идти не может. Заметим, что свойство вложимости есть отношение эквивалентности на множестве всех сжимаемых $R$-модулей. Действительно, это свойство и рефлексивно, и транзитивно. Свойство сжимаемости, очевидно, играет здесь ключевую роль. Пример алгебры Вейля демонстрирует тот факт, что кольц с точньм критически сжимаемым (несингулярным униформным) правым идеалом может обладать точными критически сжимаемыми модулями, не вкладываемыми друг в друга. А именно, алгебра Вейля есть (правая) область Оре, в силу чего является точным критически сжимаемым модулем над собой, а также, будучи собственным правьпм идеалом, является несингулярным униформным модулем опять же над собой. Однако соответствующее кольцо многочленов есть неприводимьй сингулярный модуль над алгеброй Вейля, в силу чего и не вкладывается в саму алгебру Вейля как модуль.

При более деталњном рассмотрении оказьвается, что вся проблема заключается в сингулярности. При дополнительном условии несингулярности модулей их взаимная вложимость все же имеет место.

Теорема 2. Пусть $R$ - слабо примитивное кольцо с точным критически сэиимаемым (несингулярным униформным ) правым идеалом I, тогда любые два несингулярных униформных модуля над $R$ могут быть вложены друг в друга.

В заключение автор хотел бы поблагодарить А. В. Михалева за помощь и внимание к работе.

\section{СПИСОК ЛИТЕРАТУРЫ}

[1] J. Zelmanowitz // Comm. Algebra. 1981. V. 9. № 1. Р. 23-45. [2] С. В. Зеленов // УМН. 2001. Т. 56. №3. С. 167-168. [3] С. В. Лимаренко // УМН. 2002. Т. 57. № 4. С. 181-182.

Московский государственный

Принято редколлегией университет им. М.В. Ломоносова 03.02.2003 